\title{
Pengembangan Aplikasi Deteksi Dini Pada Anak Berkebutuhan Khusus Di Sekolah Luar Biasa
}

\author{
Hendra Pradibta ${ }^{1}$; Usman Nurhasan ${ }^{2}$; Hilmy Setya Purnama Putra ${ }^{3}$ \\ 1, 2,3 Teknik Informatika, Politeknik Negeri Malang \\ ${ }^{1}$ hendra.pradibta@polinema.ac.id
}

\begin{abstract}
Children with special needs, also known as ABK are children who need proper special coaching that suits to their level of ability and needs, each of which has its own unique traits and both advantages and disadvantages. Children with special needs will be permanently abnormal if they do not receive serious supervision, education, and treatment. The diversity of children with various special needs in a variety of things that complicate teachers in recognizing the type and the delivery of appropriate education services. One of the efforts undertaken by the Ministry of Education and Culture (Kemendikbud) to giving them access to education is to build a new school unit, the Extraordinary School (SLB). SLB Tamima Mumtaz Pujon has so far been able to special needs children manually and performed by experts. Therefore, an expert system is required to help classify the various conditions of the students with special needs in order to provide them with the proper teaching method. This research applied the Forward Chaining method expert system to find the diagnostic result from the assessment answer. The Forward Chaining method on this expert system was successful and suited to the research objectives. The test results showed that the success accuracy value reached $75 \%$, and the result of the user acceptance test reached $80 \%$ of the survey results that have been filled by the school teacher.
\end{abstract}

Keywords: Children with special needs, Expert system, Forward Chaining

\begin{abstract}
ABSTRAK
Anak Berkebutuhan Khusus disingkat ABK adalah anak yang memerlukan pembinaan khusus yang sesuai dengan tingkat kemampuan dan kebutuhannya, yang masing masing memiliki ciri ciri unik serta kelebihan dan kekurangan tersendiri. Anak berkebutuhan khusus akan menjadi abnormal selamanya bila tidak mendapat penanganan, pendidikan, dan perlakuan serius. Keragaman anak berkebutuhan khusus bermacam macam sehingga menyulitkan pengajar dalam upaya mengenali jenis dan pemberian layanan pendidikan yang sesuai. Salah satu upaya yang dilakukan kementerian Pendidikan dan Kebudayaan (Kemendikbud) untuk memberikan akses pendidikan kepada mereka adalah membangun unit sekolah baru yaitu Sekolah Luar Biasa (SLB). Dalam SLB Tamima Mumtaz Pujon menganalis Anak Berkebutuhan Khusus dengan cara manual dan dilakukan oleh ahlinya dan masih belum terdokumentasi dengan rapi. Dengan demikian, dibutuhkan adanya sebuah sistem pakar guna membantu mengelompokkan berbagai kondisi anak didik berkebutuhan khusus sehingga anak didik mendapatkan metode pengajaran yang sesuai dengan kebutuhan mereka. Dalam penelitian sistem pakar ini menggunakan metode Forward Chaning yang digunakan untuk mencari hasil diagnosa dari jawaban asesmen. Penerapan Forward Chaining pada sistem pakar ini telah berjalan dengan baik dan sesuai dengan tujuan. Hasil pengujian menunjukan bahwa nilai akurasi keberhasilan mencapai $75 \%$ dan hasil dari pengujian penerimaan pengguna mencapai $80 \%$ dari hasil kuesioner yang telah diisi oleh pengajar sekolah luar biasa.
\end{abstract}

Kata kunci: Anak Berkebutuhan Khusus, Sistem Pakar, Forward Chaining 


\section{PENDAHULUAN}

Anak Berkebutuhan Khusus atau disingkat ABK adalah anak yang memerlukan pembinaan yang memadai sesuai dengan tingkat kemampuan dan kebutuhannya, yang masing masing memiliki ciri ciri unik serta kelebihan dan kekurangan tersendiri[1]. Menurut Ormord anak berkebutuhan khusus dibagi menjadi 4 yaitu anak mengalami hambatan kognitif atau akademik khusus, anak mengalami masalah sosial atau perilaku, anak mengalami keterlambatan fungsi kognitif dan sosial dan anak perkembangan kognitifnya tinggi[2]. Berdasarkan data dari Badan Pusat Statistik (BPS) tahun 2017 jumlah ABK di Indonesia mencapai 1,6 juta anak[3]. Salah satu upaya yang dilakukan kementerian Pendidikan dan Kebudayaan (Kemendikbud) untuk memberikan akses pendidikan kepada mereka adalah membangun unit sekolah baru yaitu Sekolah Luar Biasa (SLB)[3]. Anak berkebutuhan khusus sangat beragam menyulitkan pengajar dalam upaya mengenali jenis dan pemberian layanan pendidikan yang sesuai. Anak dengan gangguan emosi dan perilaku memiliki sejumlah karakter akan menghambat proses pembelajaran, bila tidak diperhitungkan dalam pemberian pendidikan pengajaran[4]. Anak berkebutuhan khusus harus mendapatkan perlakuan yang sama dalam memperoleh pendidikan yang layak dan bermutu.

Penelitian terdahulu tentang deteksi dini anak berkebutuhan khusus tingkat pendidikan anak usia dini memperoleh hasil dari penelitian ini hanya 7 responden dari 249 responden yang mengetahui tentang asesmen ABK. Sisanya sebanyak 242 responden tidak mengetahui asesmen ABK[5]. Pada penelitian tentang sistem pakar dengan metode Forward Chaning yang diterbitkan oleh Jurnal Informatika Politenik Negeri Malang menghasilkan keakuratan sebesar 86,66\%[6]. Penelitian lainnya tentang sistem pakar dengan metode Forward Chaning dapat menunjukan nilai akurasi sebesar $82 \%$ [7]. Mengacu pada penelitian diatas maka dibutuhkan sebuah sistem untuk alat bantu asesmen dengan metode Forward Chaining.

Pada SLB Tamima Mumtaz yang terletak di Desa Madiredo Kecamatan Pujon Kabupaten Malang, terdapat beberapa macam anak berkebutuhan khusus. Proses asesmennya untuk mengetahui anak berkebutuhan khusus tersebut masih menggunakan cara manual dan hanya sekilas dari penglihatan saja. Proses manual tersebut dirasa masih kurang optimal. Dan proses asesmen tersebut hanya dilakukan oleh beberapa pengajar saja. Hasil dari asesmen pun masih belum terdokumentasi secara rapi dan terarsip sehingga menyulitkan dalam proses pencarian. Dengan demikian, dibutuhkan adanya sebuah sistem pakar guna membantu proses asesmen untuk mengetahui berbagai kondisi anak didik berkebutuhan khusus. Sistem pakar sendiri mempunyai arti sistem yang berusaha mengadopsi pengetahuan manusia ke komputer, agar komputer dapat menyelesaikan masalah seperti yang biasa dilakukan oleh para ahli[6]. Sistem pakar ini berbasis website. Karena website dapat menghemat waktu dan tempat, tapi juga serta dapat diakses dimana saja[8].

Sistem ini hanya bersifat membantu proses asesmen bukan keputusan secaran final, semua keputusan tetap berada pada psikolog ataupun dokter tumbuh kembang anak karena tetap dibutuhkan pengamatan secara berkelanjutan.

\section{METODE / PERANCANGAN PENELITIAN}

\subsection{Sumber Data}

Pengumpulan data dilakukan sesuai dengan sumber dan jenis data yang diperlukan. Pengumpulan data dilakukan dengan melakukan wawancara dan observasi kepada pihak sekolah luar biasa. Dikarenakan adanya privasi maka yang diberikan adalah data anak berkebutuhan khusus hanya dengan contoh 4 anak saja.

Pada studi pustaka penelitian dilakukan dengan cara mempelajari, meneliti dan menelaah berbagai literatur yang bersumber dari buku, teks, jurnal ilmiah, situs resmi di internet dan bacaan 
yang ada kaitannya dengan topik penelitian sehingga memperoleh pengetahuan metode Forward Chaining yang digunakan dan kemampuannya dalam diagnosa awal anak berkebutuhan khusus.

Pada tahap wawancara dilakukan dengan cara bertanya kepada pihak terkait yaitu petugas SLB guna untuk mengumpulkan data. Sekolah Luar Biasa Tamima Mumtaz berdomisili di daerah Pujon Kabupaten Malang sudah terdaftar di Kemendikbud dengan NPSN 699852209 dengan nomor surat keputusan pendirian sekolah P2T/62/19.12/01XII/2018 dan memiliki izin operasional dengan nomor surat keputusan izin operasional P2T/17/19.13/01XII/2018. Sekolah Luar Biasa Tamima Mumtaz Pujon memiliki kepala sekolah atas nama Zyana Mawaddah dan dibantu oleh beberapa pengajar diantaranya Della Ayu NAP, Siti Mualifah A, Isnainingtiyas NH, Yutafitri Peni M dan Hema Pramestika C. Total anak berkebutuhan khusus pada Juli 2019 sejumlah 25 siswa. Pada sekolah ini sebelumnya hanya melakukan asesmen secara sederhana dengan melihat secara sekilas. Hasil asesmen hanya dilakukan oleh ahlinya dan data masih belum terdokumentasi dengan rapi. Maka dibutuhkan sebuah sistem guna membantu asesmen mengidentifikasi anak berkebutuhan khusus.

\subsection{Pengembangan Sistem}

Dalam metode pengembangan sistem ini akan menjelaskan langkah yang dilakukan untuk merancang dan mengembangkan sistem yang diajukan menggunakan pemodelan waterfall. Metode Waterfall merupakan pendekatan sistematis yang berurutan dalam pengembangan sebuah sistem atau perangkat lunak. Diawali dengan menganalisa kebutuhan sistem kemudian dilanjutkan dengan proses merancang desain sistem yang akan dibangun. Setelah itu dilanjutkan proses implementasi berdasarkan perencanaan dari proses sebelumnya. Apabila proses implementasi sudah terlaksana, selanjutnya proses pengujian dilakukan untuk mengetahui kesalahan yang terjadi. Tahap terakhir adalah proses perawatan dan pemeliharaan sistem agar sistem bisa digunakan dalam jangka waktu yang lama. Berikut adalah gambaran diagram dari Metode Waterfall seperti pada Gambar 1

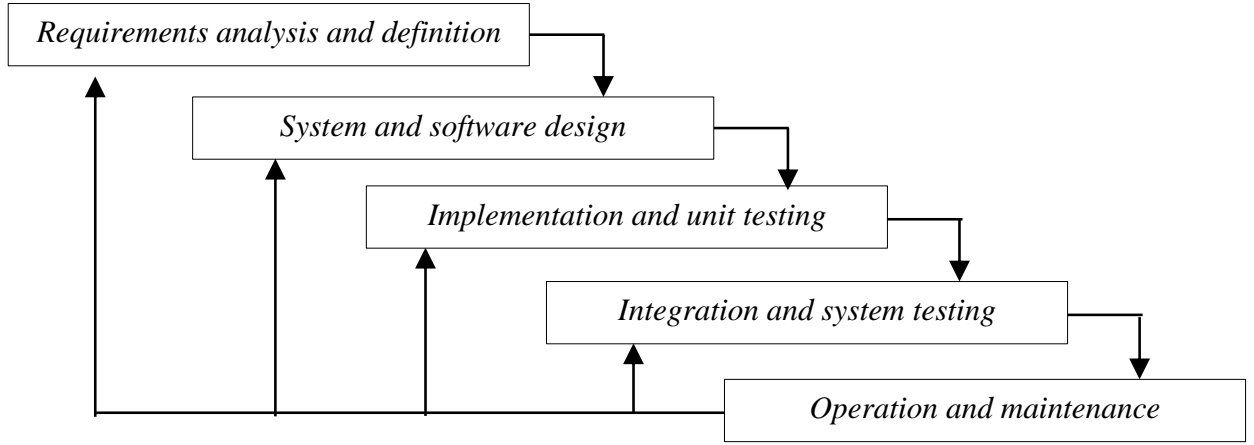

Gambar 1. Diagram Waterfall

Metode waterfall [9] memiliki tahapan sebagai berikut:

- Requirements analysis and definition

Layanan sistem, kendala, dan tujuan ditetapkanoleh hasil konsultasi dengan pengguna yang kemudian didefinisikan secara rinci dan berfungsi sebagai spesifikasi sistem.

- System and software design

Tahapan perancangan sistem mengalokasikan kebutuhan-kebutuhan sistem baik perangkat keras maupun perangkat lunak dengan membentuk arsitektur sistem secara keseluruhan. Perancangan perangkat lunak melibatkan identifikasi dan penggambaran abstraksi sistem dasar perangkat lunak dan hubungannya

- Implementation and unit testing 
Tahap ini, perancangan perangkat lunak direalisasikan sebagai serangkaian program atau unit program. Pengujian melibatkan verifikasi bahwa setiap unit memenuhi spesifikasinya.

- Integration and system testing

Unit-unit individu program atau program digabung dan diuji sebagai sebuah sistem lengkap untuk memastikan apakah sesuai dengan kebutuhan perangkat lunak atau tidak. Setelah pengujian, perangkat lunak dapat dikirimkan ke customer.

- Operation and maintenance

Tahapan ini merupakan tahapan yang paling panjang Sistem dipasang dan digunakan secara nyata Maintenance melibatkan pembetulan kesalahan yang tidak ditemukan pada tahapan-tahapan sebelumnya, meningkatkan implementasi dari unit sistem, dan meningkatkan layanan sistem sebagai kebutuhan baru.

\subsection{Forward Chaining}

Metode Forward Chaining adalah suatu metode pengambilan keputusan yang umum digunakan dalam sistem pakar. Proses pencarian dengan metode Forward Chaining berangkat dari kiri ke kanan, yaitu dari premis menuju kepada kesimpulan akhir, metode ini sering disebut data driven yaitu pencarian dikendalikan oleh data yang diberikan[10].

Metode Forward Chaining atau runut maju berarti menggunakan himpunan aturan kondisi aksi. Suatu perkalian inferensi yang menghubungkan suatu permaslahan dengan solusi disebut dengan rantai (chain). Suatu rantai yang dicari atau dilewati dari suatu permasalahan untuk memperoleh solusinya disebut dengan Forward Chaining[11]. Forward Chaining atau sering juga disebut bottom up reasoning adalah cara penarikan kesimpulan yang dimulai dengan data atau fakta yang ada lalu bergerak maju melalui premis premis untuk menuju ke kesimpulan[12].

Forward Chaining merupakan pendekatan berorientasi data. Komputer akan menganalisa permasalahan dengan mencari fakta yang cocok dengan bagian IF dari aturan IF-THEN[13]. Forward Chaining biasanya digunakan ketika suatu fakta baru ditambahkan kedalam knowledge base dan kita ingin membangkitkan konsekuensi logisnya. Dalam metode ini data digunakan untuk menentukan aturan mana akan yang akan dijalankan, kemudian aturan tersebut dijalankan.

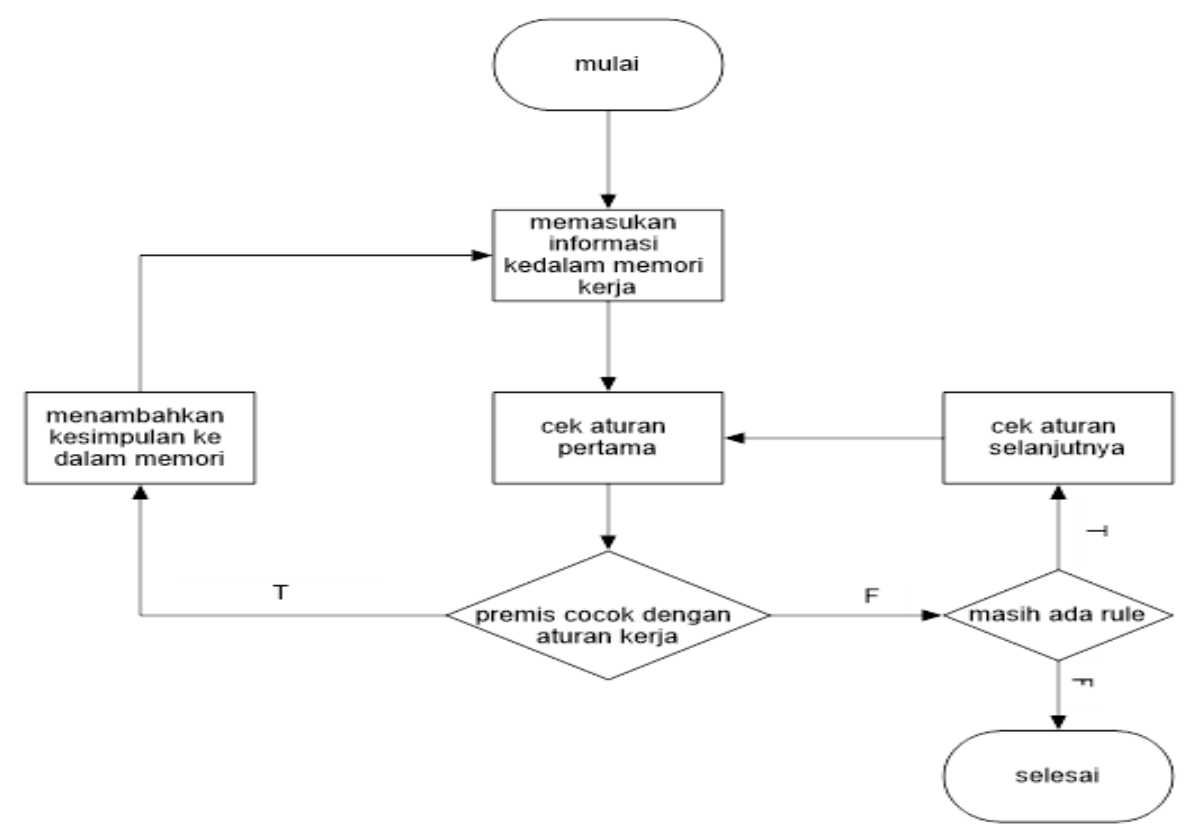

Gambar 2. Algotima Forward Chaining [13] 


\section{HASIL DAN PEMBAHASAN}

\subsection{Data Asesmen}

Pada hasil dari pembahasan dengan pihak sekolah luar biasa dan studi literatur dari jurnal ilmiah dan buku, maka di didapatkan data data gejala untuk mengatur dari rule Forward Chaining. Data gejala digunakan untuk mengolah dalam metode Forward Chaining. Dari data gejala nanti akan mengikuti rule yang telah dibuat dalam metode. Total data gejala ada 90 buah yang terdiri dari beberapa spektrum hasil diagnosa. Berikut contoh data gejala yang digunakan untuk asesmen

Tabel 1. Tabel Pengkodean Data Gejala

\begin{tabular}{|l|l|}
\hline Gejala & \multicolumn{1}{|c|}{ Keterangan } \\
\hline G01 & $\begin{array}{l}\text { kurang melihat (kabur) tidak mampu mengenali orang pada jarak 6 } \\
\text { meter }\end{array}$ \\
\hline G02 & kesulitan mengambil benda kecil di dekatnya \\
\hline G03 & tidak dapat menulis mengikuti garis lurus \\
\hline G04 & sering meraba dan tersandung waktu berjalan \\
\hline G05 & bagian bola mata yang hitam berwarna keruh/bersisik/kering \\
\hline G06 & mata bergoyang terus \\
\hline G07 & peradangan hebat pada kedua bola mata \\
\hline G08 & kerusakan nyata pada kedua bola mata \\
\hline G09 & tidak dapat membedakan cahaya \\
\hline G10 & sering memiringkan kepada dalam usaha mendengar \\
\hline G11 & banyak perhatian terhadap getaran \\
\hline G12 & tidak ada reaksi terhadap bunyi/suara di dekatnya \\
\hline G13 & terlambat dalam perkembangan bahasa \\
\hline G14 & sering menggunakan isyarat dalam berkomunikasi \\
\hline G15 & kurang atau tidak tanggap bila diajak bicara \\
\hline G16 & tidak mampu mendengar \\
\hline & \\
\hline
\end{tabular}

Dari hasil pembahasan dengan pihak sekolah luar biasa dan kajian terhadap literatur yang ada tentang topik penelitian maka di dapatkan hasil rule. Rule ini nantinya akan menghasikan sebuah hasil diagnosa anak berkebutuhan khusus. Rule Forward Chaining tertera pada tabel 2 dibawah ini

Tabel 2. Tabel Rule Forward Chaining

\begin{tabular}{|l|l|}
\hline \multicolumn{1}{|c|}{ Diagnosa } & \multicolumn{1}{c|}{ Gejala } \\
\hline Low vision & G01 and G02 and G03 and G04 and G05 and G06 and G07 and G08 \\
\hline Tunanetra & G02 and G08 and G09 \\
\hline Hard of hearing & G10 and G11 and G12 and G13 and G14 and G15 \\
\hline Tuli & G11 and G12 and G16 \\
\hline Tunagrahita ringan & G17 and G18 and G19 and G20 and G21 and G22 \\
\hline Tunagrahita sedag & G23 and G24 and G25 and G26 and G27 and G28 and G29 \\
\hline Tunagrahita berat & G30 and G31 and G32 and G33 and G34 and G35 \\
\hline Polio & G36 and G37 and G38 and G39 and G40 \\
\hline Cerebal palcy & G36 and G37 and G38 and G39 and G40 and G41 and G42 \\
\hline Tunalaras & G43 and G44 and G45 and G46 \\
\hline
\end{tabular}




\begin{tabular}{|l|l|} 
Anak berbakat & $\begin{array}{l}\text { G47 and G48 and G49 and G50 and G51 and G52 and G53 and G54 } \\
\text { and G56 and G57 and G59 and G60 and G61 and G62 and G63 and } \\
\text { G64 }\end{array}$ \\
\hline $\begin{array}{l}\text { Anak lamban } \\
\text { belajar }\end{array}$ & G65 and G66 and G67 and G68 and G69 \\
\hline Disleksia & G70 and G71 and G72 and G74 and G81 \\
\hline Disgrafia & G72 and G73 and G74 and G75 and G76 and G77 \\
\hline Diskalkulia & G74 and G78 and G79 and G80 and G81 and G82 \\
\hline Autis & G83 and G84 and G85 and G86 and G87 and G88 and G89 and G90 \\
\hline
\end{tabular}

\subsection{Hasil Pengujian}

Pengujian dilakukan dengan membandingkan hasil diagnosa dari sistem ini dengan hasil dari pakar yang di sekolah luar biasa. Tampilan dibawah ini merupakan tampilan awal pada tahap proses yang diwajibkan mengisi nama, umur dan juga nomor hp orangtua.

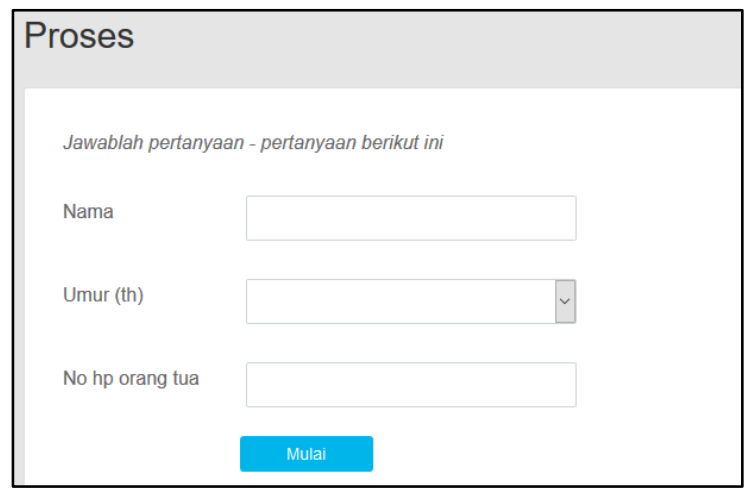

Gambar 3. Tampilan Proses 1

Halaman ini menu proses yang mana admin dapat melakukan proses asesmen untuk tanya jawab. Asesmen berupa pertanyaan dari list gejala dijawab dengan ya, tidak atau tidak tau. Dari hasil jawaban inilah yang nantinya untuk proses Forward Chaining

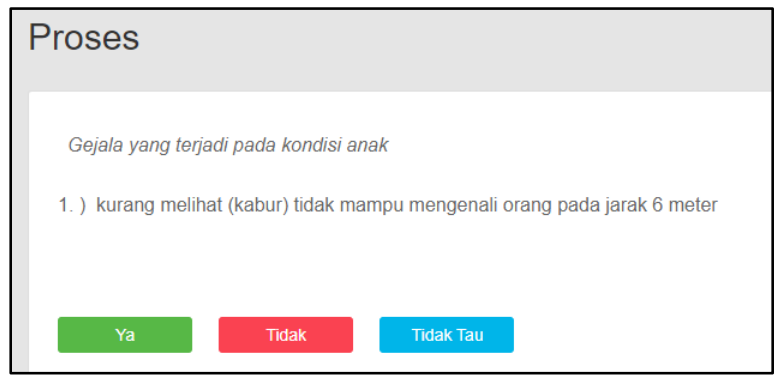

Gambar 4. Tampilan Proses 2

Halaman antarmuka hasil dari proses asesmen. Dari daftar gejala tersebut dibuat alur Forward Chaining sehingga keluar hasil konsultasi. Hasil tersebut juga dapat dikirimkan ke whatsapp orang tua sesuai dengan nomor yang sudah dimasukan. Hasil asesmen ini juga dapat disimpan. 


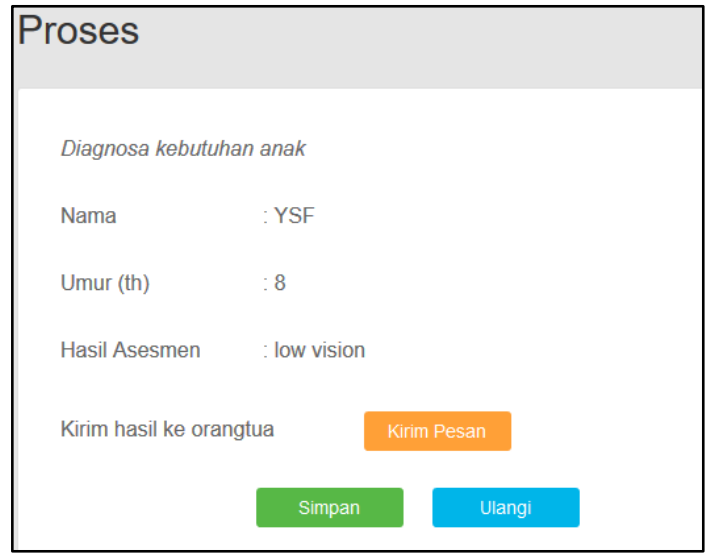

Gambar 5. Tampilan Proses 3

Pengujian sistem dilakukan untuk membuktikan apakah metode Forward Chaining yang diterapkan dalam penentuan kebutuhan khusus pada anak memang sesuai dengan hasil menurut pakar. Pengujian akurasi metode Forward Chaining membandingkan hasil uji dari sistem pakar ini dengan pendapat dari pihak SLB. Dikarenakan adanya perjanjian dengan pihak SLB maka nama akan disamarkan.

Pada anak yang bernama (inisal) YSF umur 8 tahun. YSF berkebutuhan khusus kurang mampu melihat pada jarak 6 meter, kesulitan mengambil benda kecil di dekatnya, tidak bisa menulis mengikuti garis, sering meraba saat berjalan, bagian bola mata hitam keruh dan sering bergoyang, bagian bola mata mengalami sedikit kerusakan, dan juga peradangan pada bola mata.

Dari data diatas di dapatkan

G01 = kurang melihat (kabur) tidak mampu mengenali orang pada jarak 6 meter

G02 = kesulitan mengambil benda kecil di dekatnya

$\mathrm{G} 03$ = tidak dapat menulis mengikuti garis lurus

G04 = sering meraba dan tersandung waktu berjalan

G05 = bagian bola mata yang hitam berwarna keruh/bersisik/kering

G06 = mata bergoyang

G07 = peradangan hebat pada kedua bola mata

G08 = kerusakan nyata pada kedua bola mata

Sesuai hasil gejala yang di dapatkan maka di lanjutkan dengan rule Forward Chaining sesuai dengan Tabel 2 Tabel Rule Forward Chaining

\section{IF G01 AND G02 AND G03 AND G04 AND G05 AND G06 AND G07 AND G08 THEN} DIAGNOSA

Dari hasil rumus tersebut di dapatkan hasil Low Vision

Berikut hasil lengkap pengujian. Dikarenakan adanya perjanjian dengan pihak SLB maka nama akan disamarkan.

Tabel 3. Tabel Uji Coba

\begin{tabular}{|l|l|l|l|l|l|}
\hline No & Nama & Umur & Sistem Pakar & SLB & Hasil \\
\hline 1 & YSF & 8 & Low vision & Low vision & Sesuai \\
\hline 2 & NR & 6 & Autis & Disgrafia & Tidak sesuai \\
\hline 3 & FHR & 9 & Diskalkulia & Diskalkulia & Sesuai \\
\hline 4 & WWN & 7 & Disgrafia & Disgrafia & Sesuai \\
\hline
\end{tabular}

Keterangan tabel 3 
Nama : Nama siswa anak berkebutuhan khusus (disamarkan)

Umur : Umur siswa anak berkebutuhan khusus

Sistem Pakar : Hasil pengujian dari sistem ini dengan metode Forward Chaining

SLB : Hasil dari pakar pihak sekolah luar bisa

Hasil : Perbandingan antara hasil sistem pakar dan SLB apakah sesuai atau tidak sesuai

Persentase hasil pengujian sebagai berikut.

$$
\begin{aligned}
\text { Nilai Akurasi } & =\frac{\text { Jumlah Data Akurat }}{\text { Jumlah Seluruh Data }} \times 100 \% \\
& =\frac{3}{4} \times 100 \% \\
& =75 \%
\end{aligned}
$$

Dapat disimpulkan bahwa tingkat akurasi pengujian berdasarkan 4 data sampel yang bernilai 75\% menunjukkan bahwa penentuan anak berkebutuhan khusus menggunakan metode Forward Chaining dalam sistem pakar ini berfungsi dengan baik.

Dari autisme tersebut tidak sama dengan hasil diagnosa asli karena ada beberapa gejala yang masih belum masuk. Dan tidak selalu pasti data list pada gejala sudah pasti terjadi untuk melakukan asesmen. Asesmen diagnosa harus dilakukan secara rutin dan dilakukan pengamatan secara berkelanjutan. Asesmen di sistem ini hanya bersifat membantu pakar.

\subsection{Proses Hasil Kuesioner Pengujian}

Pada pengujian sistem ini dilakukan untuk memberi hak kepada pegawai Sekolah Luar Biasa Tamima Mumtaz Pujon Malang dalam memberi penilaian serta mengetahui tingkat kepuasan kepada pengguna sistem pakar untuk mendiagnosa tahap pertama pada Sekolah Luar Biasa Tamima Mumtaz Pujon Malang. Dalam pengujian ini peneliti menggunakan User Acceptence Test (UAT) yang berbentuk kuesioner dengan jumlah 6 responden yang dilibatkan adalah pengajar SLB dengan 9 pertanyaan dan kategori penilaian yang digunakan yaitu sangat tidak setuju (1), tidak setuju (2), cukup (3), setuju (4), dan sangat setuju (5).

Tabel 4. Tabel Hasil Data Kuesioner

\begin{tabular}{|l|c|c|c|c|c|}
\hline \multicolumn{1}{|c|}{ Pertanyaan } & STS & TS & C & S & SS \\
\hline $\begin{array}{l}\text { Sistem ini membantu dalam mendiagnosa anak berkebutuhan } \\
\text { khusus }\end{array}$ & & & & 2 & 4 \\
\hline Sistem dapat menjalankan fungsinya & & & 1 & 4 & 1 \\
\hline Sistem login dapat dijalankan & & & & 4 & 2 \\
\hline Menu menu pada aplikasi mudah dijalankan & & & 2 & 4 & \\
\hline Informasi pada aplikasi mudah dimengerti & & 2 & 4 & \\
\hline Letak menu pada aplikasi mudah dipahami & & & 1 & 5 & \\
\hline Aplikasi ini secara keseluruhan memuaskan & & & 4 & 1 \\
\hline $\begin{array}{l}\text { Aplikasi dapat membantu pengelompokan anak berkebutuhan } \\
\text { khusus }\end{array}$ & & & 5 & 1 \\
\hline Aplikasi mampu menunjang kinerja pada sekolah luar biasa & & & 1 & 3 & 2 \\
\hline
\end{tabular}

Pada pertanyaan pertama "Sistem ini membantu dalam mendiagnosa anak berkebutuhan khusus" 2 orang menjawab setuju dan 4 orang menjawab sangat setuju

Pengujian kesioner yang dilakukan menggunakan skala Likert [14]. Kemudian dilakukan proses perhitungan hasil jawaban kuesioner yang di dapat dengan cara mengalikan setiap poin 
jawaban dengan bobot yang sudah ditentukan dengan table bobot nilai. Sebagai contoh perhitungan jawaban responden pada pertanyaan 1 dan 2 sebagai berikut.

Pertanyaan nomor 1

Responden menjawab sangat setuju : 4 x $5=20$

Responden menjawab setuju : 2 x $4=8$

Responden menjawab cukup : 0 × $3=0$

Responden menjawab tidak setuju : 0 × $2=0$

Responden menjawab sangat tidak setuju : 0 × $1=0$

Total skor $=20+12+0+0+0=28$

Untuk mendapatkan hasil interpretasi, harus diketahui dulu skor tertinggi dan skor terendah untuk item penilaian. Jumlah skor tertinggi ialah 30 dan skor terendah ialah 6 . Tahap selanjutnya menentukan total skor presentase kelayanan (PK) dengan rumus sebagai berikut:

$P K(\%)=\frac{\text { skor yang diobservasi }}{\text { skor yang diharapkan }} \times 100 \%$

Maka penyelesaian akhir dari hasil keseluruhan dari total skor skor presentase kelayanan (PK) dapat dilihat di gambar 6 dibawah ini. Contoh perhitungan jawaban responden pada nomor 1 yaitu:

Pertanyaan nomor 1

$P K(\%)=\frac{28}{30} \times 100 \%=93 \%$

Maka didapatkan presentase kelayanan (PK) kuesioner pertanyaan nomor 1 mencapai 93\%.

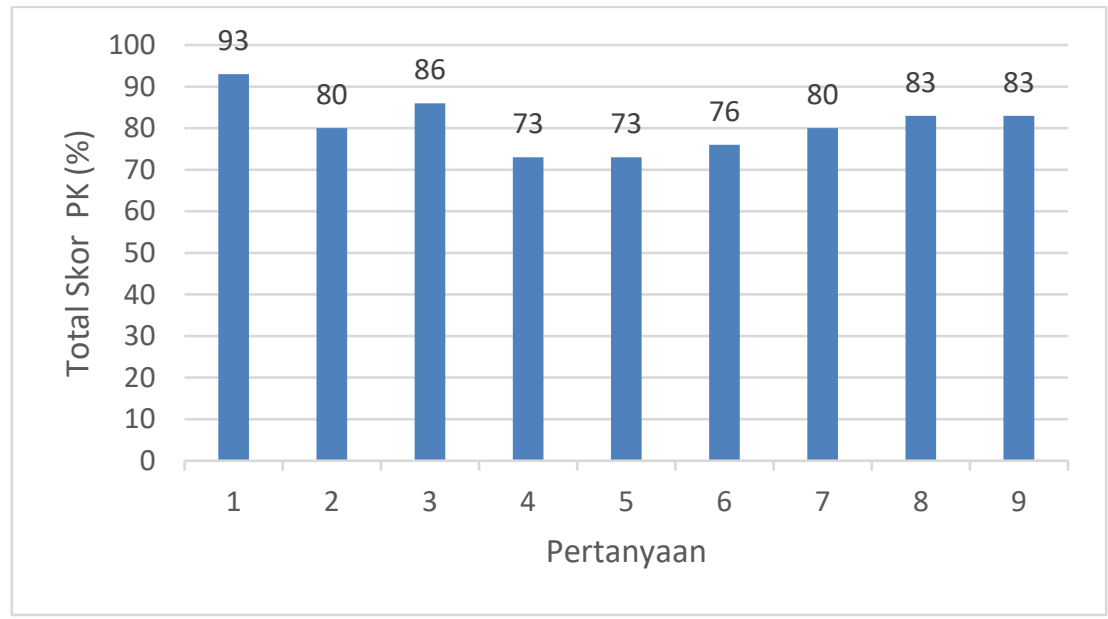

Gambar 6. Grafik Hasil Akhir Kuesioner

Tabel 5. Tabel Pesentase Kelayakan[14]

\begin{tabular}{|c|l|}
\hline $\begin{array}{c}\text { Indeks Pesentase } \\
\text { kelayakan }\end{array}$ & \multicolumn{1}{|c|}{ Nilai } \\
\hline$<21 \%$ & $\begin{array}{l}\text { Sangat Tidak } \\
\text { Layak }\end{array}$ \\
\hline $21 \%-40 \%$ & Tidak Layak \\
\hline $41 \%-60 \%$ & Cukup \\
\hline $61 \%-80 \%$ & Layak \\
\hline $81 \%-100 \%$ & Sangat Layak \\
\hline
\end{tabular}


Berdasarkan hasil rata rata hasil pengujian User Aceptance Test dengan skala Likert yang berupa kuesioner menunjukan angka $80 \%$, maka dapat disimpulkan bahwa sistem sudah layak sesuai dengan kategori Tabel Pesentase Kelayakan. Dan sistem ini Pengembangan Aplikasi Deteksi Dini Pada Anak Berkebutuhan Khusus di Sekolah Luar Biasa ini dapat diterima dengan baik oleh pengguna.

\section{KESIMPULAN DAN SARAN}

Berdasarkan hasil dari perancangan Pengembangan Aplikasi Deteksi Dini pada Anak Berkebutuhan Khusus di Sekolah Luar Biasa berbabasis website menggunakan metode Forward Chaining, maka dapat diambil kesimpulan bahwa sistem ini telah dibangun dapat memberikan bantuan asesmen yang dapat menentukan diagnosa awal bagi anak berkebutuhan khusus. Sistem pakar deteksi dini ini memiliki presentase user acceptance test / penerimaan pengguna sebesar $80 \%$ yang menandakan responden dari kuesioner setuju akan fitur fitur pada aplikasi yang telah disediakan oleh penulis guna membantu diagnosa tahap pertama pada anak berkebutuhan khusus. Sistem ini menghasilkan $75 \%$ keberhasilan dari 4 anak yang telah diuji. Jadi dapat disimpulkan sistem ini sudah cukup baik.

\section{DAFTAR PUSTAKA}

[1] P. D. S, M. I. Suriansyah, and S. Novianti, "Deteksi Dini Autisme Menggunakan Fuzzy Tsukamoto," pp. 329-334, 2012.

[2] N. U. R. Eva, Psikologi Anak Berkebutuhan Khusus. FPPsi, 2015.

[3] R. Nugroho, Kristiawan P.A; Sijabat, "Gaya Hidup Yang Mempengaruhi Kesehatan Anak Berkebutuhan Khusus di SLB Negeri Salatiga,” J. Keperawatan Muhammadiyah, vol. 2, no. 2, 2017.

[4] A. Mahabbati, "Identifikasi Anak dengan Gangguan Emosi dan Perilaku di Sekolah Dasar," Pendidik. Khusus Issn 1858-0998, vol. 2, no. 2, pp. 1-14, 2006.

[5] Z. Suryaningrum, Cahyaning; Ingarianti, Tri Muji; Anwar, "Pengembangan Model Deteksi Dini Anak berkebutuhan Khusus (ABK) Pada Tingkat Pendidikan Anak Usia Dini (PAUD) di Kota Malang," JIPT, vol. 04, no. 01, pp. 62-74, 2016.

[6] A. J. A. Amrullah and Ekojono, "SISTEM PAKAR DIAGNOSA PENYAKIT PARU-PARU DENGAN," J. Inform. Polinema, vol. 2, pp. 13-17, 2015.

[7] B. F. Yanto, I. Werdiningsih, and E. Purwanti, "Aplikasi Sistem Pakar Diagnosa Penyakit Pada Anak Bawah Lima Tahun Menggunakan Metode Forward Chaining," J. Inf. Syst. Eng. Bus. Intell., vol. 3, no. 1, p. 61, 2017.

[8] A. M. Putri, I. P. Wardhani, and S. Widayati, "Aplikasi Profil Perusahaan Digital Berbasis Web," vol. 12, no. 2, pp. 165-171, 2019.

[9] D. Sarkawi and P. S. Sekretari, "PERANCANGAN APLIKASI PENJUALAN DENGAN METODE WATERFALL," vol. 11, no. 1, pp. 9-24, 2018.

[10] D. T. Kusuma, S. Karmila, T. A. Nova, and J. T. Informatika, "FORWARD CHAINING DALAM DIAGNOSIS PENYAKIT," vol. 11, no. 2, pp. 164-178, 2018.

[11] E. Tristiani, R. Ariyanto, and D. Puspitasari, "Sistem Pakar diagnosa Penyakit Gigi dan Mulut Menggunakan Metode Forward Chaining (Studi Kasus :Rs.Brawijaya Malang)," Sist. Pakar diagnosa Penyakit Gigi dan Mulut Menggunakan Metod. Forw. Chain. (Studi Kasus Rs.Brawijaya Malang), 2014. 
[12] F. N. Salisah, L. Lidya, S. Defit, J. S. Informasi, F. Sains, and U. I. N. Suska, "Sistem Pakar Penentuan Bakat Anak Dengan Menggunakan Metode Forward Chaining," J. Rekayasa dan Manaj. Sist. Inf., vol. 1, no. 1, pp. 62-66, 2015.

[13] E. H. Wijaya and N. Hidayat, "Diagnosis Penyakit Cabai Dengan Menggunakan Metode Forward Chaining - Dempster-Shafer," vol. 2, no. 12, pp. 7202-7208, 2018.

[14] A. Pramuaji and M. Munir, "PENGEMBANGAN MEDIA PEMBELAJARAN INTERAKTIF PADA MATERI PENGENALAN COREL DRAW SEBAGAI SARANA," Elinvo, vol. 2, no. $2,2017$. 